\title{
Homoimplante de costela conservada em solução supersaturada de açúcar a $300 \%$ ou em açúcar in natura na reconstituição experimental de costelas em gatos
}

\author{
Homoimplants rib preserved in $\mathbf{3 0 0} \%$ hyper saturated sugar solution or sugar in natura for experimental \\ reconstitution of ribs in cats
}

\author{
Josaine Cristina da Silva Rappeti ${ }^{\mathrm{I}}$ Ney Luis Pippi ${ }^{\mathrm{II}}$ Fabrício de Vargas Arigony Braga ${ }^{\mathrm{I}}$ \\ Giancarlo Santini de Souza ${ }^{\mathrm{III}}$ Giane D'Avila Coelho ${ }^{\mathrm{IV}}$ Giane Magrini Pigatto ${ }^{\mathrm{IV}}$ Deisi Novosad ${ }^{\mathrm{II}}$ \\ Marta Cristina Thomas Heckler ${ }^{\mathrm{IV}}$ Giovani Krolikowski ${ }^{\mathrm{I}}$ Gustavo Amêndola ${ }^{\mathrm{I}}$ Carmem Godoy ${ }^{\mathrm{V}}$ \\ Rodrigo Otavio do Canto Cardona
}

\section{RESUMO}

O objetivo deste estudo foi avaliar a eficiência do açúcar em diferentes formas de conservação para ossos, verificar a eficiência do implante de costela conservada na reconstituição de defeito torácico, avaliar a fixação da costela com agulha de cateter, e monitorar a estabilidade $e$ a dinâmica do tórax após o implante. Além disso, buscouse avaliar clinicamente, macroscopicamente, histologicamente e radiograficamente o material implantando. Os 16 implantes utilizados foram costelas homólogas conservadas em açúcar in natura (Ga) ou a 300\% (Gb), na reconstituição de costelas de gatos. Os animais foram separados em dois grupos: Ga (8), utilizando açúcar "in natura” e o Gb (8), solução a 300\%. Foi realizado defeito no terço médio do lado direito do tórax de 16 gatos adultos, os quais foram fixados no leito receptor por meio de agulha de cateter. A porcentagem de incorporação dos implantes foi de $91,7 \%$ aos 60 dias no Ga e 73,9\% no Gb. Foram verificadas, em diferentes etapas, leve reabsorção do implante em 29,2\% no Ga e de 37,8\% no Gb. Não foi observado qualquer caso de eliminação ou de infecção. É possível concluir que o implante ósseo homólogo de costela conservado em açúcar “in natura” ou a 300\% é uma opção viável para a reconstituição da parede torácica de gatos.

Palavras-chave: implante ósseo, reconstituição torácica, açúcar, gato.

\section{ABSTRACT}

This study was aimed at evaluating the use of a homologous bone implant preserved sugar in natura (Ga) (8) or in $300 \%$ sugar solution $(G b)$ (8) for reconstitution of the thoracic wall in 16 cats, involving three ribs. A costal defect was made on the right side of the thoracic wall and the preserved ribs were used as homologous bone implants for the correction of this defect. These ribs were fixed to the receptor by means of a catheter needle. The animals were clinically evaluated by $X$ rays and histology. The percentual of implant incorporation at 60 days was $91.7 \%$ in the $G a$ and $73.9 \%$ in the Gb. A mild resorption was observed at different times, $29.2 \%$ in the in natura sugar group, and $37.8 \%$ in the $300 \%$ sugar group. No case of infection or rejection was observed in the evaluated period. The homologous rib bone implant preserved in sugar in natura or in $300 \%$ solution is efficient for the reconstitution of costal wall in cats.

Key words: bone implant, sugar, thoracic reconstituition, cats.

\section{INTRODUÇÃO}

O traumatismo torácico é uma afecção muito comum em pequenos animais, chegando a $10 \%$ das lesões em trauma (CROWER Jr. et al., 2005). BRIAN et al. (2000) correlacionaram traumas ortopédicos e fraturas de costelas e encontraram que, de 75 gatos estudados, 67 (89\%) apresentavam fraturas costais.

Em um estudo realizado por OLSEN et al. (2002), os métodos de fixação interna de costelas utilizados foram pino intramedular, cerclagens e suturas de aproximação. Em intervenções cirúrgicas

IPrograma de Pós-graduação em Medicina Veterinária (PPGMV), Universidade Federal de Santa Maria (UFSM), Santa Maria, RS, Brasil. E-mail: josainerappeti@yahoo.com.br. Autor para correspondência.

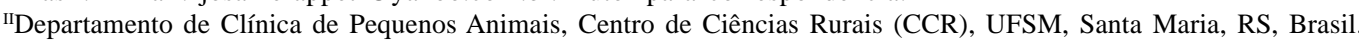

IIICurso de Medicina Veterinária, DCPA, CCR, UFSM, Santa Maria, RS, Brasil.

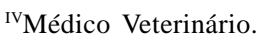

vDepartamento de Clínica de Grandes Animais, CCR, UFSM, Santa Maria, RS, Brasil. 
ortopédicas, materiais alternativos têm sido utilizados para o reparo de fraturas, como citaram ERDMANN et al. (2002), que empregaram agulhas como pinos intramedulares. Para a redução de fratura de costela, é necessário um pino intramedular de pequeno calibre (FOSSUM, 2005). RAPPETI et al. (2004) utilizaram agulha de cateter para a osteossíntese de costelas em gatos. Esse material também foi utilizado por RAPPETI (2006) em cães, para reduzir fraturas costais.

Os defeitos torácicos que envolvem três ou mais costelas podem ser reconstituídos por malhas protéticas (BONATH, 1996) ou material biológico, como o pericárdio de eqüino conservado em glicerina (STOPIGLIA et al., 1986). A cartilagem auricular heteróloga conservada em glicerina a $98 \%$ foi empregada para a reconstituição da parede torácica em gatos (RAPPETI et al., 2003) e também em coelhos (FREITAS et al., 2004), sendo que OHNO et al. (1998) valeram-se de prótese de liga de titânio.

Os homoenxertos ósseos corticais são empregados em vários meios e métodos de conservação de ossos (STEVENSON, 1998). Quanto aos métodos de conservação de implantes ósseos, numerosas são as alternativas, sendo citados a glicerina ou o mel por GAIGA (2002), a tintura de iodo a $2 \%$ por PINTO Jr. (1995) e o mel por AMÊNDOLA(2001) eALIEVI(2006).

Para OLIVEIRA et al. (1999), os materiais utilizados como enxerto ósseo podem atuar por três mecanismos, que são: osteogênese, osteoindução e osteocondução. Os enxertos não contribuem para a osteogênese, mas são capazes de promover a osteoindução e originar uma estrutura de suporte e osteocondução (ALEXANDRE, 1983). Para SINIBALDI (1989), o mais importante é o contato entre o enxerto e o osso receptor e a fixação rígida. A rejeição de enxertos é o resultado da sensibilização do receptor por antígenos (BROWN \& CRUESS, 1982).

Substâncias como o açúcar têm sido usadas desde os tempos mais antigos em ferimentos, com excelentes resultados (MARTINNEZ et al., 1998). A presença dessa substância aumenta a pressão osmótica, criando condições desfavoráveis ao crescimento da maioria das bactérias (PRATA \& FUKUDA, 2001). CENTERO NETO et al. (1997) obtiveram bons resultados com o açúcar em concentrações iguais ou superiores a $250 \%$, e MAZZANTI et al. (2003) utilizaram-no como meio de conservação numa concentração de 300\%.

Diante dos aspectos considerados, têm-se como objetivos: avaliar o açúcar em duas concentrações como meio de conservação para ossos; verificar a eficiência do implante de costela conservada na reconstituição de defeito torácico; avaliar a fixação costal com agulha de cateter; monitorar a estabilidade e a dinâmica do tórax após o implante, avaliando-o clinicamente, macroscópica, histológica e radiograficamente.

\section{MATERIAL E MÉTODOS}

Foram utilizados 16 gatos, adultos hígidos, obtidos no Biotério Central da UFSM. Eles foram alojados em gaiolas individuais, permanecendo com ração comercial e água ad libitum. Os gatos foram separados em dois grupos de oito animais cada, sendo que, no grupo a (Ga), a forma de conservação dos implantes foi açúcar in natura; e, no grupo b (Gb), solução de açúcar a 300\%. Os tempos observados foram aos 60(GaI e GbI) e 120 dias (GaII e GbII) de pósoperatório.

As costelas coletadas foram retiradas de gatos encaminhados para eutanásia, livres de neoplasias, trauma no gradil torácico ou doenças infecto-contagiosas. A musculatura inserida nas costelas foi removida, e estas foram estocadas em frascos de vidro seco contendo a solução saturada de açúcar a 300\%, ou açúcar in natura.

A solução a $300 \%$ foi preparada com 300 gramas de açúcar diluído em 100ml de água destilada (300g:100ml) e homogeneizada manualmente. As costelas permaneceram totalmente imersas nessa solução à temperatura ambiente. Na outra forma de conservação, as costelas ficaram cobertas com açúcar cristal in natura, sempre da mesma marca comercial ${ }^{\mathrm{a}}$. Após dois dias, foram renovados os meios, e as costelas permaneceram nesses meios no mínimo por 30 dias.

O implante foi rehidratado com iodo polivinil pirrolidona (PVPI) aquoso e Ringer com lactato (RL) em proporção de 1:50 (1ml de PVPI e 50ml de RL) por um período de 24 horas antes do ato operatório. Em seguida, essa solução foi substituída por RL até o momento do seu uso. O iodo usado foi da mesma marca comercial $^{\mathrm{b}}$.

Os animais foram submetidos a jejum sólido de $12 \mathrm{~h}$ e hídrico de duas horas. A medicação préanestésica foi com sulfato de atropina, diazepam e cetamina. A indução anestésica foi com cetamina e a manutenção da anestesia com halotano. Foi utilizada cefalotina e, no transoperatório, sulfato de fentanila. Esse protocolo foi instituído para todos os procedimentos cirúrgicos.

Os gatos foram preparados para a cirurgia asséptica. Foi realizada a toracotomia abordando o terço médio do tórax, no lado direito.Pela radiografia préoperatória, o cateter 20G ou 22G foi selecionado, 
conforme o tamanho de cada costela. Foi produzido um defeito de 1,0 a $1,5 \mathrm{~cm}$, em três costelas, que variou entre a 9a $, 8^{\underline{a}}, 7^{a}, 6^{\underline{a}}$ e a $5^{\underline{a}}$. Antes do procedimento cirúrgico, as costelas foram medidas, e os implantes confeccionados conforme o tamanho estipulado utilizado um paquímetro estéril.

Para fixar o implante, foi utilizada uma pinça de Lane na extremidade da costela. O implante foi fixado com uma agulha de cateter, sendo que todos os cateteres utilizados foram da mesma marca comercialc .
A agulha foi introduzida no segmento ventral do corpo da costela, no sentido normógrado, num ângulo de $30^{\circ}$ (Figura1A). Após atingir a medular, foi introduzida no implante (Figura 1B) até atingir o segmento dorsal da costela e ficar ancorada.

A porção inferior da agulha que sobrou foi curvada utilizando-se um alicate, que manteve a mesma no local onde foi introduzida até a formação de um gancho, quando a sua extremidade foi cortada. Quando necessário, o gancho foi realizado nas duas

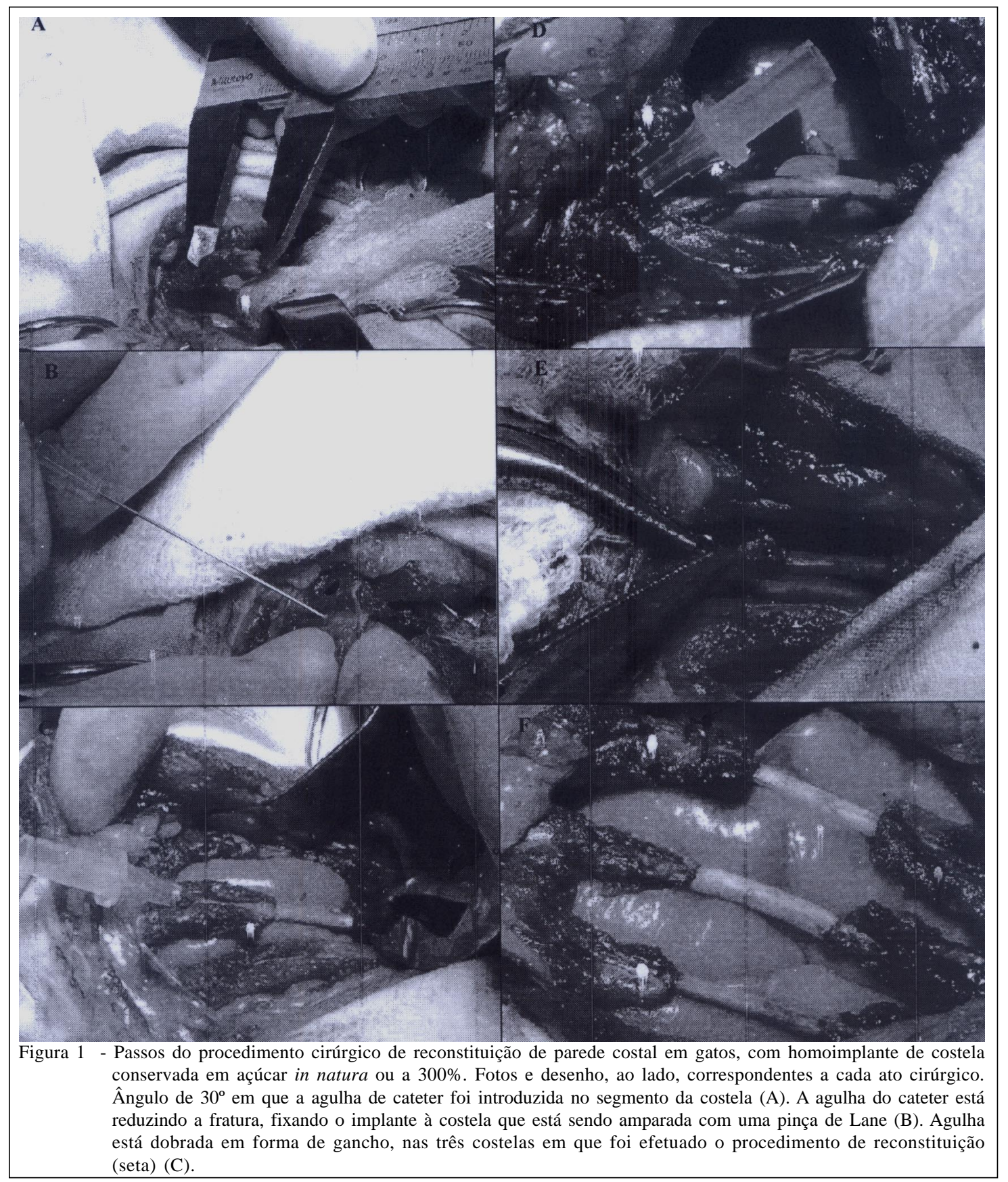

Ciência Rural, v.37, n.6, nov-dez, 2007. 
extremidades da agulha. Foram implantadas três costelas conservadas (Figura 1C). Foram feitas suturas festonadas do músculo do serratil dorsal e grande dorsal com fio poliglactina 910, de diâmetro 4-0. A redução do espaço morto foi com o mesmo fio em pontos isolados simples, e a pele foi fechada com fio mononáilon 4-0.

A remoção do ar residual foi feita por insuflação pulmonar, ao ser dado o último ponto do primeiro plano de sutura e, quando necessário, por toracocentese. Ao término da cirurgia, foi administrada lidocaína intrapleural. No período pós-operatório, foi utilizado tramadol a cada seis horas por quatro dias e cetoprofeno por três dias. Os pontos foram removidos entre o $7^{\circ}$ e $10^{\circ}$ dias após o ato operatório.

Os animais foram observados diariamente quanto a padrão respiratório, presença ou não de seroma, aspecto da ferida, deiscência, demonstração de dor, presença de apetite, defecação e quanto ao comportamento. Estes dados foram avaliados nos primeiros três dias de pós-operatório, conforme classificação subjetiva de dor (Tabela 1).

O controle radiográfico pós-operatório foi realizado aos 45, 60, 90 e 120 dias, conforme cada grupo. Aos 60 dias, as agulhas foram retiradas. Na presença de dois ganchos, foram realizadas duas incisões de pele, uma dorsal e outra ventral. O corte do gancho dorsal permitiu a remoção da agulha pela incisão ventral.

Para a biópsia, foi realizado o acesso torácico de maneira rotineira. As amostras das costelas com o implante foram coletadas de quatro gatos com 60 dias (dois do GaI e dois do GbI) e quatro com 120 dias (dois do GaII e dois do GbII). Os animais selecionados foram aqueles que não apresentaram aderência do pulmão com o implante, verificado através da avaliação por toracoscopia (RAPPETI, 2006). A toracorrafia foi efetuada com sutura festonada, aproximando o músculo grande dorsal. Os demais planos foram fechados com técnica rotineira. Por três dias foram utilizados tramadol e cetoprofeno. As amostras foram coloradas por Hematoxilina e Eosina (HE) e observadas em microscopia óptica de luz.

\section{RESULTADOSE DISCUSSÃO}

Os implantes do Ga apresentavam melhor facilidade de manipulação, comparados aos do Gb, que estavam mais rígidos, embora a hidratação de $24 \mathrm{~h}$ tenha sido considerada suficiente, pois não ocorreu qualquer caso de fratura à manipulação. O tempo de rehidratação empregado foi o mesmo usado por RAISER (2000) ao rehidratar o tendão de cães.

Após dois dias de permanência dos implantes nos meios, os mesmos foram trocados, visto que o açúcar in natura tornava-se úmido. Segundo CENTERO NETO et al. (1997), isso ocorre devido ao açúcar criar um meio hiperosmolar, por possuir ação osmótica, provocando desidratação e morte celular do tecido conservado.

A fração da agulha inserida no segmento ventral da costela do receptor foi pelo menos do mesmo tamanho no segmento dorsal, e a medida do seu tamanho foi feita com a parte de silicone do cateter, como sugerido por RAPPETI (2004). Ao chegar na curvatura da costela, este ficou ancorado, pois a sua extremidade em bisel serviu para esta finalidade, mantendo estável o implante.

Os cateteres de diâmetro 20G foram utilizados na maioria dos gatos (11), devido a seu maior comprimento e resistência. Das agulhas com diâmetro $22 \mathrm{G}$, que foram usadas nas costelas, uma quebrou, uma migrou e outras três entortaram. A agulha atingiu de 60 a 75\% da porção mais estreita da porção medular, como preconizaram TUDURY et al. (2003).

Os comprimentos das costelas variaram de no máximo 6,5cm a no mínimo 4cm, e os implantes foram

Tabela 1 -Avaliação subjetiva de dor segundo classificação numérica de acordo com a estimativa de dor nos gatos que sofreram retiradas cirúrgicas em parede torácica.

\begin{tabular}{|c|c|c|}
\hline Classificação & Avaliação & Características \\
\hline 0 & Completa analgesia (sem dor) & $\begin{array}{l}\text { Nenhum sinal de dor, não sente a palpação quando a ferida cirúrgica é tocada, } \\
\text { movimenta-se livremente, musculatura torácica relaxada, respiração tóraco- } \\
\text { abdominal, urina, come e defeca. }\end{array}$ \\
\hline 1 & Boa analgesia & $\begin{array}{l}\text { Sinais de pouca dor quando a ferida é tocada, não morde, respiração tóraco- } \\
\text { abdominal, com predominância abdominal, urina, procura a comida, porém não } \\
\text { come. }\end{array}$ \\
\hline 2 & Moderada analgesia & $\begin{array}{l}\text { Sinal de incômodo ao toque da ferida, mia e restringe os movimentos, movimentos } \\
\text { respiratórios superficiais, interage pouco com as pessoas não aceita alimento. }\end{array}$ \\
\hline 3 & Ausência de analgesia & $\begin{array}{l}\text { Nítidos sinais de dor, tenta morder quando a ferida é tocada, musculatura tensa do } \\
\text { tórax, não acha posição para deitar, não aceita alimento, vocaliza, pupilas dilatadas, } \\
\text { olhar fixo, orelhas para trás, padrão respiratório abdominal. }\end{array}$ \\
\hline
\end{tabular}


de $1,5 \mathrm{~cm}$ a $1,0 \mathrm{~cm}$. Segundo SINIBALDI (1989), o tamanho do implante não é o fator mais importante na incorporação. Neste estudo, buscou-se uma homogeneização, sendo que o maior e o menor implantes alcançaram 22,28\% e 21,48\% do comprimento da costela, respectivamente.

Em dois gatos, os defeitos foram mais ventrais e, em outro, mais dorsais na costela. Embora tenha-se tentado fazer os defeitos no terço médio do corpo das costelas, ao se retirar de 2 a 3mm, pode-se formar um defeito direcionado tanto dorsal quanto ventral, pois são estruturas muito pequenas. Na costela que recebeu o implante mais ventral, foi necessária uma cerclagem, embora não tenha sido verificada nenhuma complicação, porém, no outro animal, a agulha migrou.

No gato, cujo defeito foi mais dorsal, foi necessário curvar as duas extremidades da agulha. RAPPETI (2006) cita que existe a possibilidade de ocorrer fratura no segmento ventral ou a agulha migrar quando houver pouca estrutura óssea para ela ser inserida, sendo necessária a reintervenção cirúrgica. FOSSUM (2005), para prevenir esta complicação, dobrou as duas extremidades do pino. Optou-se, neste estudo, por colocar cerclagem no segmento dorsal, com o objetivo de prevenir fraturas, fato recomendado por RAPPETI (2006), ao realizar osteossíntese de costela em cães.

Segundo parâmetros descritos anteriormente, na avaliação subjetiva de dor, foi observado grau 1 no primeiro e no segundo dia e grau zero no terceiro dia de pós-operatório, ou seja sem dor.

No Ga, aos 60 dias, dois implantes, em um total de 24, apresentavam imagem radioluscente, correspondendo a 8,34\%. A avaliação da reabsorção foi evidenciada aos 90 dias em apenas um implante, correspondendo a 4,17\%. Já no Gb, em um total de 23 implantes, ao se avaliar a reabsorção em 45 dias, foram encontrados dois $(8,70 \%)$, aos 60 dias, foram encontrados dois $(8,70 \%)$ e, aos 90 dias, quatro (17,39\%), o que correspondeu a um total de 34,79\%. PINTO Jr. (1995) observou que a radiodensidade do implante ósseo em seu experimento diminuiu gradativamente a partir de três meses. AMÊNDOLA (2001) encontrou a diminuição da densidade dos implantes aos 30 dias, a qual se manteve até os 75 dias, em média. Além disso, foi observada maior reabsorção nas interfaces implante/receptor, fato explicado devido à atividade osteoclástica focal das superfícies do implantes antecedendo a atividade osteoblástica (STEVENSON \& HOROWITZ, 1992).

Num total de 47 implantes, ocorreu somente uma fratura no segmento dorsal (2,13\%). BURCHARDT (1983) comenta que em até $20 \%$ dos animais podem ser encontradas essas complicações, sugerindo que esse índice indica mínima ou insignificante diferença imunológica entre o doador e o receptor. Logo, 12,77\% e 2,13\% estão dentro do esperado.

Na avaliação histológica foram encontradas uma taxa de união entre as interfaces implante/receptor de $91,67 \%$ no Ga e 73,91\% no Gb, apresentando atividade osteoclástica e presença de osteócitos viáveis no local do implante. Foi considerada alta taxa de incorporação nos dois grupos, verificando osteocondução, com continuidade entre os tecidos, formando tecido ósseo sobre o implante. O processo de incorporação é o envolvimento do osso necrótico por um osso novo viável, o osso necrótico é reabsorvido e o tecido ósseo novo vai se formando (BURCHARDT, 1983).

Os resultados obtidos mostraram a evolução da incorporação dos implantes, pois, aos 60 dias, foi verificado osso trabecular em direção ao implante em dois gatos. Segundo AMÊNDOLA(2001), o tempo de 60 dias de pós-operatório é suficiente para verificar o que ocorre com o tecido ósseo implantado.

Nos animais em que houve consolidação, haviam osteócitos viáveis na área de interface costelaimplante, porém não em toda a sua extensão. As células inflamatórias mais encontradas foram linfócitos e plasmócitos. Dos oito animais avaliados, sendo três com 120 dias, dois apresentaram reabsorção óssea. Os tecidos ósseos conservados agem como suporte para a formação de um novo osso e, para que isso ocorra, passam por vários graus de absorção osteoclástica e substituição progressiva por parte do osso hospedeiro (PIERMATTEI \& FLO, 1999).

\section{CONCLUSÕES}

Foi possível concluir que: as costelas conservadas em açúcar cristal ou em 300\% por um período não inferior a 30 dias podem ser utilizadas para reconstituir falhas ósseas experimentais em gatos sem induzir reações de eliminação; a técnica de fixação dos implantes com agulha de cateter é eficaz e proporciona estabilidade do tórax e retorno dos parâmetros respiratórios fisiológicos; os exames radiográfico e histológico apresentam coerência na evolução pósimplantação caracterizada por reparação óssea aos 60 dias de pós-operatório.

\section{FONTES DE AQUISIÇÃO}

(a) Açúcar Cristal ${ }^{\circledR}$, Indústria Brasileira.

(b) Germi-Rio, Bioquímica, São José do Rio Preto, SP.

(c) Cateter intravascular periférico Jelco, Medex, São Paulo, SP.

Ciência Rural, v.37, n.6, nov-dez, 2007. 


\section{REFERÊNCIAS}

ALEXANDRE, J.W. Use of combination of cortical bone allografts and cancellous bone autografts to replace massive bone loss in fresh fractures and selected nonunions. Journal of the American Animal Hospital Association, v.19, n.5, p. 671-678,1983.

ALIEVI, M.M. Implante ósseo cortical alógeno conservado em mel na reconstituição de falha óssea diafisária em fêmur de cães. 2006. 88f. Tese (Doutorado em Medicina Veterinária) - Universidade Federal de Santa Maria.

AMÊNDOLA, G.F. Correção de defeito ósseo femoral em cães utilizando implante ósseo cortical homólogo conservado em mel. 2001. 46f. Dissertação (Mestrado em Medicina Veterinária) - Universidade Federal de Santa Maria.

BONATH, K.H. Thoracic wall closure: thoracic closure. In: LIPOWITZ, A.J. et al. Complications in small animal surgery. Baltimore: Willians \& Wilkins, 1996. Cap.8, p.229-239.

BRIAN, J.K. et al. Intrathoracic and concurrent orthopedic injury associated with traumatic rib frature in cats: 75 cases (1980-1998). Journal American Veterinary Medical Association, v.216, n.1, p.51-54, 2000.

BROWN, K.L.B.; CRUESS, R.L. Bone and cartilage transplantation in orthopedic surgery. Journal of Bone and Joint Surgery, v.64A, n.2, p.270-279,1982.

BURCHARDT, $\mathrm{H}$. The biology of bone graft repair. Clinical Orthopedics and Related Research, n.174, p.28-41, 1983.

CENTERO NETO, A.A.C. et al. Concentração bactericida do açúcar em culturas de escherichia coli. Revista do Colégio Brasileiro de Cirurgiões, v.24, p.151-154, 1997.

CROWER JR., D.T. et al. Trauma torácico. In: RABELO, R.C.; CROWE JR, D.T. Fundamentos de terapia intensiva veterinária em pequenos animais conduta no paciente crítico. Rio de Janeiro: L.F. Livros de Veterinária, 2005. Cap.18, p.173-183.

ERDMANN, R.L. et al. Utilização de material alternativos para cirurgias ortopédicas em aves silvestres na clínica veterinária santa clara, cascavel - Paraná. In: CONGRESSO DA SOCIEDADE DE ZOOLÓGICOS DO BRASIL. 2., 2002, Porto Alegre. Anais... Porto Alegre: Sociedade de Zoológicos do Brasil, 2002. p.33.

FOSSUM, T.W. Endoscopia de cavidades corporais. In: Cirurgia de pequenos animais. 2.ed. São Paulo: Roca, 2005. Cap. 6, p.127-132.

FREITAS, P.M.C. et al. Reparo da parede torácica de coelhos com cartilagem auricular de cães preservada em glicerina a $98 \%$ e com pedículo dos músculos serrátil ventral e grande dorsal. Brazilian Journal of Veterinary Research and Animal Science, v.41, p.156-157, 2004.

GAIGA, L.H. Osteossíntese de úmero por xenoenxerto ósseo preservado em glicerina $98 \%$ ou mel em pombos domésticos (Columba lívia). 2002. 45f. Dissertação (Mestrado em Medicina Veterinária) - Universidade Federal de Santa Maria, Santa Maria.
MARTINNEZ, T.C.N. et al. Avaliação in vitro da eficácia do açúcar na inibição do crescimento bacteriano. Arquivo da Escola de Medicina Veterinária, v.19, n.1, p.109-118, 1998.

MAZZANTI, A. et al. Herniorrafia diafragmática em cão com pericárdio bovino conservado em solução supersaturada de açúcar. Arquivo Brasileiro de Medicina Veterinária e Zootecnia, v.55, n.6, p.677-684, 2003.

OHNO, K. et al. Chest wall repair with a titanium instrument. Annals of Thoracic Surgery, v.66, n.5, p.1805-1806, 1998.

OLIVEIRA, R.C. et al. Efeito da temperatura de desproteinização no reparo de osso cortical bovino microgranular, avaliação microscópica e bioquímica da resposta celular em subcutâneo de ratos. FOB, v.7, n.3/4, p.85-93, 1999.

OLSEN, D. et al. Clinical management of flail chest in dogs and cats: a retrospective study of 24 cases (1989-1999). Journal of the American Animal Hospital Association, v.38, p.315-320, 2002.

PIERMATTEI, D.L.; FLO, G.L. Enxertos ósseos. In Manual de ortopedia e tratamento das fraturas dos pequenos animais. 3.ed. São Paulo: Manole, 1999. Cap.3, p.139-145, 1999

PINTO Jr., H.S. Utilização de enxertos ósseos cortical homólogo preservado em tintura de iodo a $2 \%$ na reparação de fraturas cominutivas de ossos longos de cães. 1995. 75f. Tese (Doutorado Medicina Veterinária) Faculdade de Medicina Veterinária e Zootecnia da Universidade de São Paulo.

PRATA, L.F; FUKUDA, R.T. Fundamentos de higiene e inspeção de carnes. Jaboticabal: UNESP, 2001. 326p.

RAISER, A.G. Homoimplante ortotópico de tendão calcâneo comum, preservado em glicerina a $98 \%$, e tratado com radiação laser arseneto de gálio, em cães. 2000. 80f. Tese (Doutorado em Medicina Veterinária) Universidade Federal de Santa Maria, Santa Maria.

RAPPETI, J.C.S. et al. Reconstituição experimental da parede torácica de gatos com implante heterólogo de cartilagem auricular conservada em glicerina a 98\%. Ciência Rural, v.33, n.6, p.1089-1094, 2003.

RAPPETI, J.C.S. Material alternativo para redução de fraturas costais em gatos - Palestra. In: CONGRESSO BRASILEIRO DE CLÍNICOS VETERINÁRIOS DE PEQUENOS ANIMAIS; 25., 2004, Gramado, RS. Anais... Porto Alegre: ANCILVEPA, 2004. 1 CD.

RAPPETI, J.C.S. Reconstituição experimental da parede torácica em gatos - Palestra. In: CICLO DE ATUALIZAÇÃO EM MEDICINA VETERINÁRIA, 12., 2006, Lages-SC. Anais... Lages: UDESC, 2006. 1 CD.

RAPPETI, J.C.S. Homoimplante de costela conservada em solução supersaturada de açúcar a $300 \%$ ou em açúcar in natura na reconstituição experimental de costelas 
em gatos (Felis catus). 2006. 91f. Tese (Doutorado em Medicina Veterinária) - Universidade Federal de Santa Maria.

SINIBALDI, K. Evalution of full cortical allografts in 25 dogs. Journal of the American Veterinary Medical Association, v.194, n.11, p.1570-1577, 1989.

STEVENSON, S. Enxertos ósseos. In: SLATTER, D. Manual de cirurgia de pequenos animais. 2.ed. São Paulo: Manole, 1998. V.2, cap.127, p.2006-2017.
STEVENSON, S.; HOROWITZ, M. Current concepts review the response to bone allografts. Journal of Bone and Joint Surgery, v.74A, n.6, p.939-950, 1992.

STOPIGLIA, A.J. et al. Réparátion chirurgicale de la paroi thoracique du drieu. Le Point Veterinaire. v.18, n.97, p.239243, 1986.

TUDURY, E.A. et al. Instrumentais e métodos de redução e fixação de fraturas. Recife, PE: Universidade Federal Rural de Pernambuco, 2003. 46p. 